\title{
Infiltration-induced Slope Instability: a multi-scale approach
}

\author{
Francesca Casini $^{1, a}$, Amin Askarinejad $^{2}$ and Sarah M. Springman ${ }^{3}$ \\ ${ }^{1}$ Università di Roma Tor Vergata, Dipartimento di Ingegneria Civile e Ingegneria Informatica, 00133 Roma, Italy \\ ${ }^{2} T U$ Delft, Faculty of Civil Engineering and Geosciences, Geoengineering section, Delft, The Netherlands \\ ${ }^{3}$ ETH Zürich, Institute for Geotechnical Engineering, Zürich, Switzerland
}

\begin{abstract}
Precipitation, together with erosion and earthquakes, have been recognized as the main triggering factors of shallow landslides. However, there are relatively few well-documented cases where direct relationships could be established between occurrence and features of shallow landslides, the rainfall characteristics (e.g. intensity, duration) and water retention curves. A field experiment has been performed on a steep forested slope located on the east-facing banks of the river Rhine in Ruedlingen, northern Switzerland. The aim of the experiments was to study the triggering mechanisms of the landslides induced by rainfall. The pore pressure and the degree of saturation, which are linked through the water retention curve, represent two of the main variables affecting the mechanical behaviour of unsaturated soils, and their relationships to rainfall are complex. The difference in the determination of water retention curves at different scales are analysed in this paper for Ruedlingen soil together with their effects on mechanical behaviour at multi-scale.
\end{abstract}

\section{Introduction}

Rainfall induced landslides are one of the major natural hazards in Switzerland [1-2-3-4]. Experience in Hong Kong shows that they occur more frequently when short-duration rainfall is of high intensity [5-6]. The location of the failure is strongly influenced by spatial and temporal variations in seepage induced by pore water pressure [6].

The slope stability depends directly on the distribution of water and of the pore pressure inside its mass. These factors are affected by the hydraulic properties of unsaturated soils, such as the water retention curve and the hydraulic conductivity function [e.g. 7-8].

A landslide triggering experiment was carried out near Ruedlingen in North East Switzerland, on a slope overlooking the river Rhine, in autumn 2008 and spring 2009. This attempted to replicate the effects of a heavy rainfall event from May 2002, in which $100 \mathrm{~mm}$ rain fell in 40 minutes [9], causing 42 superficial landslides.

The slope was subjected to extreme rainfall by artificial means in October 2008 over a period of 4 days, with a rainfall intensity of 15 $\mathrm{mm} / \mathrm{h}$ for the first 2 days, and an intensity of 30 $\mathrm{mm} / \mathrm{h}$ for the rest. The sprinklers were distributed at constant spacing along the central line of the slope. Some surface movements were detected during this extreme event, although failure did not occur. Subsequently, a range of measures was implemented, such as relocating the distribution of the sprinklers to provide more rainfall to the upper part of the slope, so that a failure mechanism was triggered in March 2009, incorporating about $150 \mathrm{~m}^{3}$ of debris $[1,4,10,11]$.

It is essential to understand the hydromechanical (HM) behaviour of the unsaturated soils subject to rainfall to be able to prevent the landslides and the HM factors affecting the loss of strength. HM behaviour observed in situ and in the laboratory are compared, highlighting common trends and discrepancies in preventing shallow landslides being induced by rainfall.

\section{Landslide test site and soil classification}

The experimental area is located on an eastfacing slope on the banks of the river Rhine

\footnotetext{
${ }^{\mathrm{a}}$ Corresponding author: francesca.casini@uniroma2.it
} 
(Figure 1a). The altitude is about 350 metres above sea level. The average gradient was determined using a total station theodolite to be $38^{\circ}$ with maximum of $43^{\circ}$ in the middle of the slope. The surface is slightly concave; the middle longitudinal line is 0.3 to $0.5 \mathrm{~m}$ lower than the sides, except that the slope drains marginally to the north at the bottom [4]. According to DPL tests (Dynamic Probing with a "Light" $10 \mathrm{~kg}$ weight), the bedrock level is reached between $0.5 \mathrm{~m}$ and $5 \mathrm{~m}$. The site is located in the Swiss lowlands and the underlying rock consists mainly of a sequence of Molasse, which is the naturally cemented sediment that was deposited in the foreland basin of the Alps under successive fresh and saltwater regimes.

Three cluster locations (Figure 1b) were instrumented with tensiometers, Decagons, TDRs, piezometers, rain gauges, pressure cells, and deformation probes. The instruments were installed from 15 to $150 \mathrm{~cm}$ depth below the surface at each of three cluster locations.

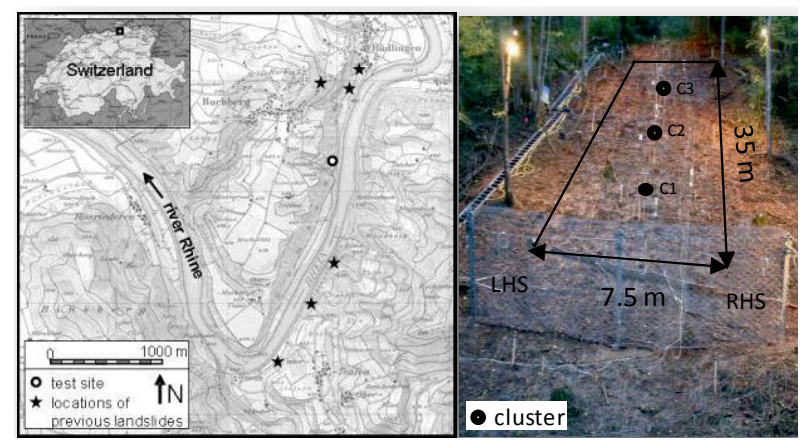

Figure 1. Location of the site: (a) detailed map; (b) test site, geometry and 3 instrument clusters (C1-C3) (after [10]).

Combined sprinkling and dye tracer tests were carried out at the three different locations, revealing a high infiltration capacity of the soil. No overland flow was observed during the sprinkling at any of the locations. In all of the soil profiles, staining of the soil was mainly homogeneous and little preferential flow was visible, although deeper percolation into the Molasse sandstone was revealed by the observation of several stained joints below the subsoil. The experimental slope was originally forested, with covertures of circa $80 \%$ to heights between $5-20 \mathrm{~m}$. Shrubs up to $1-5 \mathrm{~m}$ high and ground vegetation each cover about $50 \%$ of the surface.
In order to understand the in situ triggering experiment, an extensive soil investigation was conducted to understand how the strength is mobilised in the soil and how this may be related to change in water content and void ratio in the slope $[10,12]$. The investigation includes tests on both undisturbed and reconstituted soil samples, in saturated and unsaturated conditions. Water retention curves and hydraulic conductivity functions have been obtained in the laboratory at different scales [12] and in situ [8]. Mobilised shear strength has been investigated at multi-scale, with standard and modified shear box apparatuses in saturated and unsaturated conditions $[13,14$, 15]. Unsaturated and saturated statically compacted and natural specimens have been tested under triaxial stress conditions to characterise the mechanical behaviour of the soil at different gravimetric water contents in a triaxial stress path apparatuses and to link the mechanical behaviour with the soil-water retention curve obtained under suctioncontrolled conditions with different void ratios $[7,10]$.

Moreover, a series of Unsaturated Constant Shear Drained (U-CSD) triaxial tests were performed by [11] to replicate the stress path that a soil element experiences during the rise of pore water pressure in a slope, during and/or after a rainfall event.

The soil can be classified as medium to low plasticity silty sand (ML) according to USCS. Activity of the soil comes from the chloriticsmectitic clay fraction [14]. The activity, $I_{A}$, is higher than 1.25 in the upper part of the soil profile and decreases from $\mathrm{I}_{\mathrm{A}}=1.25$ to $\mathrm{I}_{\mathrm{A}}=$ 0.75 below $1 \mathrm{~m}$ depth. The clay fraction increases with depth from $4 \%$ at shallow depths to $10 \%$ at about $2 \mathrm{~m}$. The silt fraction also increases with depth from $25 \%$ to $32 \%$, while the sand fraction decreases from $67 \%$ to $56 \%$. The increase of the fine fraction with depth may be due to internal erosion, sedimentological and morphological reasons, and downward transport promoted by infiltrating water [10].

\section{Water retention curve: laboratory versus in situ results}


The water retention curves (WRCs) under suction controlled conditions have been obtained on specimens compacted at different void ratios [7]. A wetting path has been followed at three void ratios (Figure 2), while results for the drying path have also been obtained for a specimen with a void ratio $\mathrm{e}=$ 0.85. Particular attention has been paid to the evolution of the wetting path dependent on the void ratios, because it is the typical path experienced under field conditions during a rainfall event. The evolution of the WRC with void ratio plays a fundamental role in the evaluation of the stability of steep slopes due to the coupling effects of suction and degree of saturation (e.g. $[2,7])$.
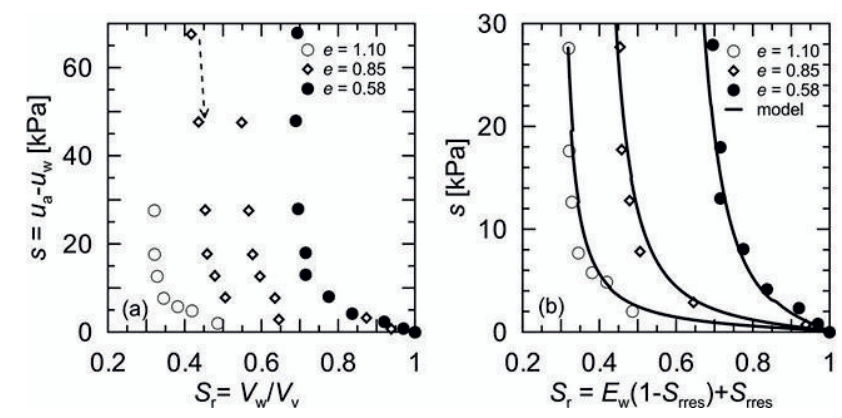

Figure 2. Water retention curves of Ruedlingen silty sand: (a) experimental data at different void ratios along wettingdrying paths; (b) modelling of the wetting paths (after [11]).

The wetting water storage mechanism has been described using a modified van Genuchten [17] model (after [12]) in terms of dimensionless water ratio $E_{\mathrm{W}}=E_{\mathrm{w}}(\mathrm{s}, \mathrm{n})$ as follows:

$$
\begin{aligned}
& E_{w}=\frac{e_{w}-e_{\text {wres }}}{e-e_{\text {wres }}}=\left\{1+[s / P(n)]^{1 /[1-l(n)]}\right\}^{-l(n)} \\
& P(n)=P_{0} \exp ^{b\left(n_{0}-n\right)} ; l(n)=l_{0} \exp ^{c\left(n_{0}-n\right)}
\end{aligned}
$$

where $e_{\mathrm{w}}=V_{\mathrm{w}} / V_{\mathrm{s}}, V_{\mathrm{s}}$ is the volume of solids, $e_{\text {wres }}$ and $S_{\text {rres }}$ are the residual water void and saturation ratios, $P(n)$ and $l(n)$ are functions depending on porosity $n$, via parameters $b$ and $c$. The parameters obtained by fitting the experimental WRCs are reported in Table 1 and compared in Figure 2b, in terms of $S_{\mathrm{r}}$ versus $s$.
Table 1. WRC parameters

\begin{tabular}{|c|c|c|c|c|}
\hline$n_{0}$ & $P_{0}(\mathrm{kPa})$ & $b$ & $l_{0}$ & $l$ \\
\hline 0.524 & 0.7 & 9 & 0.5 & -2.5 \\
\hline
\end{tabular}

The model fits the experimental results well over the variation of void ratio and in the range of suction investigated.

In reality, the rainfall was not uniformly distributed, as had been approximated in [1]. The artificial rainfall was applied in situ by 10 equi-spaced sprinklers, located on the middle longitudinal line of the test-field. The lower sprinklers experienced higher hydraulic heads as the water was supplied from the upper part of the slope.

Insitu WRCs and those derived in the laboratory are presented in Figures 3 for a depth of $30 \mathrm{~cm}$ in cluster 2 . The first wetting branch (W1) shows higher values of suction at the same VWC compared with first drying curve (D1), which is in contrast with the literature data and theory on hysteretic behaviour [18]. This can be attributed to increase in volume during wetting and to the heterogeneity in the flow paths [8]. Similar trend are reported for different depths (see [8]).

The drying branch of WRC for clusters 1 and 2 at different depths are enlarged and shown in Figure 4. The curves obtained for depths of 120 $\mathrm{cm}$ and $90 \mathrm{~cm}$ in cluster 1 show air entry values of around $2.2 \mathrm{kPa}$, which is lower than that implied by the laboratory WRC. This can be caused by void ratio differences between soil at these depths and the void ratio of the natural specimen tested in the laboratory $(\mathrm{e}=0.8)$.

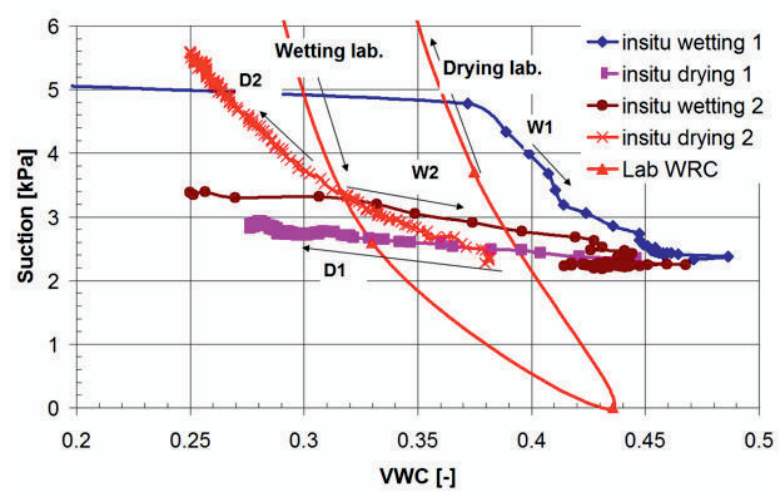

Figure 3. In situ WRC cluster 2 at depth of $30 \mathrm{~cm}$ compared with laboratory results (after [8]) 
Similarly, in cluster 2 (Figure 5) at a depth of $120 \mathrm{~cm}$, the air entry value is comparable to the value at $150 \mathrm{~cm}(\sim 3.0 \mathrm{kPa})$, while the soil has a lower void ratio at $120 \mathrm{~cm}$ compared with that at $150 \mathrm{~cm}$. The trend lines of dry branch of WRC in situ are less steep than in the laboratory.

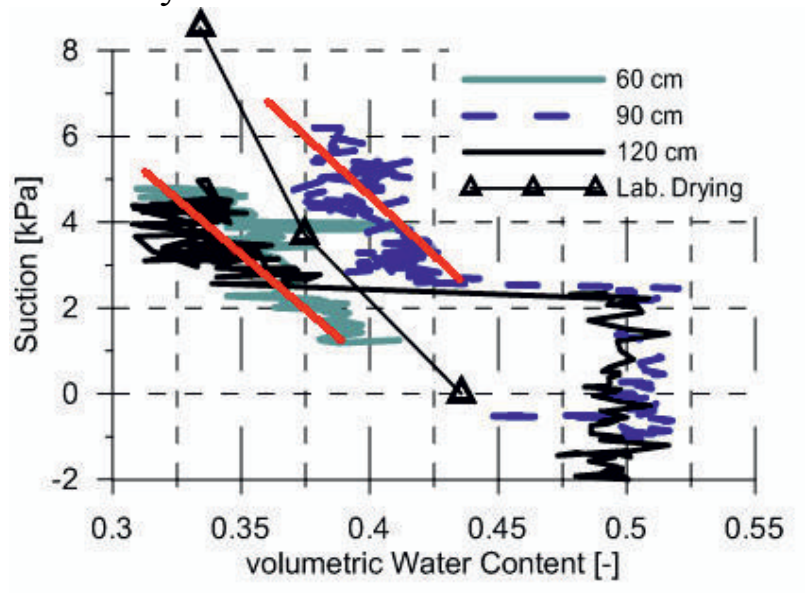

Figure 4. Drying curve of in situ WRC for cluster 1 compared with laboratory results (after [8])

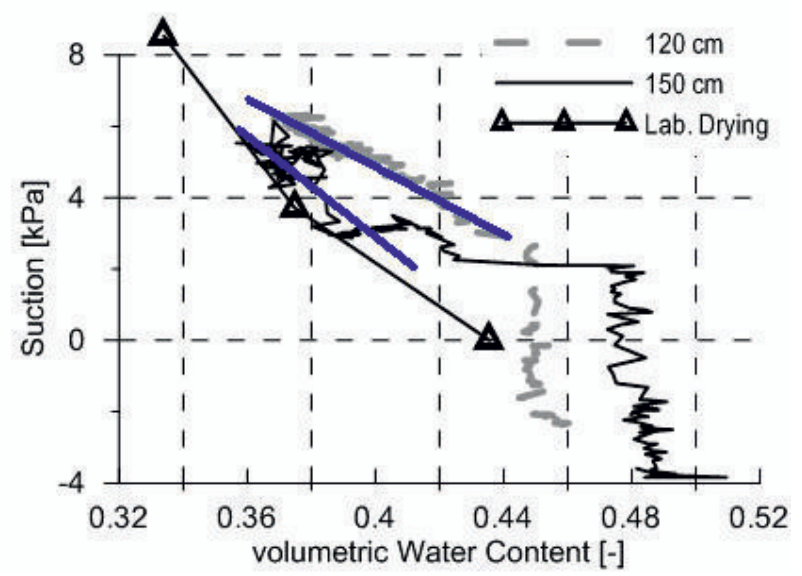

Figure 5. Drying curve of in situ WRC for cluster 2 compared with laboratory results (after [8])

\section{Mechanical behaviour: laboratory versus in situ experiments}

An extensive soil investigation was conducted to understand how the strength is mobilised in the soil and how this may be related to change in water content and void ratio in the slope (e.g. 7; 10; 14; 15). The investigation includes triaxial tests and shear tests on both undisturbed and reconstituted soil samples.

\subsection{Triaxial stress path tests}

The main objectives of the experimental programme were to characterise the behaviour expected during rainfall infiltration, under unsaturated and saturated conditions, and to investigate the potential for instability of the Ruedlingen soil during shearing to failure. Conventional stress path tests were performed on specimens with three gravimetric water contents, as well as on paths approaching those experienced in the field (more details in [7, 10]).

Standard drained (CIDC) and undrained (CIUC) shear compression tests were performed, together with constant axial load shear compression tests under decreasing isotropic stress (by increasing pore water pressure). In the latter case, both drained (CADCAF) and undrained (CADCAUF) conditions were studied after an initial drained stage (CAD), to analyse the influence of the hydraulic boundary conditions on the eventual failure mechanism of the soil specimens $[7,10]$.

The results of the constant axial load phase for the same water content and different $\eta=$ $q / p^{\prime}$ values are reported in Figure 6 in the $p^{\prime}-q$ and $\varepsilon_{\mathrm{q}}-\varepsilon_{\mathrm{v}}$ planes, where the mean effective stress is defined as $p^{\prime}=p-u_{\mathrm{a}}+S_{\mathrm{r}}\left(u_{\mathrm{a}}-u_{\mathrm{w}}\right)$ with the suction obtained from equation 1 , knowing the water ratio $E_{\mathrm{w}}$. The total stress was decreased for specimens TX3 and TX4, while maintaining a constant axial load, which promotes a slight increase in volumetric strain (Figures 6a-b). This is likely to be the result of elastic swelling as the stress path moves inside the yield locus.

After an initial contractant phase, a more pronounced increase of the swelling volumetric strain is observed for specimen TX2, which was compressed to $\eta=0.375$, denoting a dilatant mode of ultimate failure with plastic volume increase. The response of the specimen to an increase in stress obliquity $(\eta \geq 0.75)$ during the consolidation phase shows that the magnitude of strain in axial extension is suppressed in favour of greater magnitude of strain in radial extension, as the deviator strain is always positive; whereas it is negative initially for specimen TX2 with $\eta=0.375$.

The specimens with $\mathrm{w}=0.25$ (TX6, TX7, and TX8; Figures $6 \mathrm{c}-\mathrm{d}$ ) exhibit a significant increase in volume with increasing shear strain for two of the three obliquities investigated. Plastic volumetric strains increase as the stress path approaches and crosses the critical state 
line, demonstrating a dilatant mode of ultimate failure. The same behaviour is observed for saturated specimens TX11 and TX12, while specimen TX10, with $\eta=0.375$, exhibits less pronounced decreases of deviatoric stress (Figures 6e-f).

The framework proposed by [19] (after [20]) has been adopted to study the failure mechanisms of loose and dense sand samples. They concluded that the instability can occur under both undrained and drained conditions as long as the stress path leads the stress state into the zone of instability, distinguishing the occurrence of conditional stability (continuously decreasing mean effective stress in drained conditions) from that of run-away failure (under undrained conditions due to the progressive increase of pore-water pressure). The validity of the framework has been extended to unsaturated conditions, with summary data reported in Figure 7. The void ratio at critical state $e_{\mathrm{csl}}=v_{\mathrm{csl}}-1$ is evaluated through $v_{\mathrm{cs}}=N_{\mathrm{M}}(\chi)-\lambda \ln p^{\prime}$ with parameter $\chi=S_{\mathrm{r}}$ (more details in [7]).
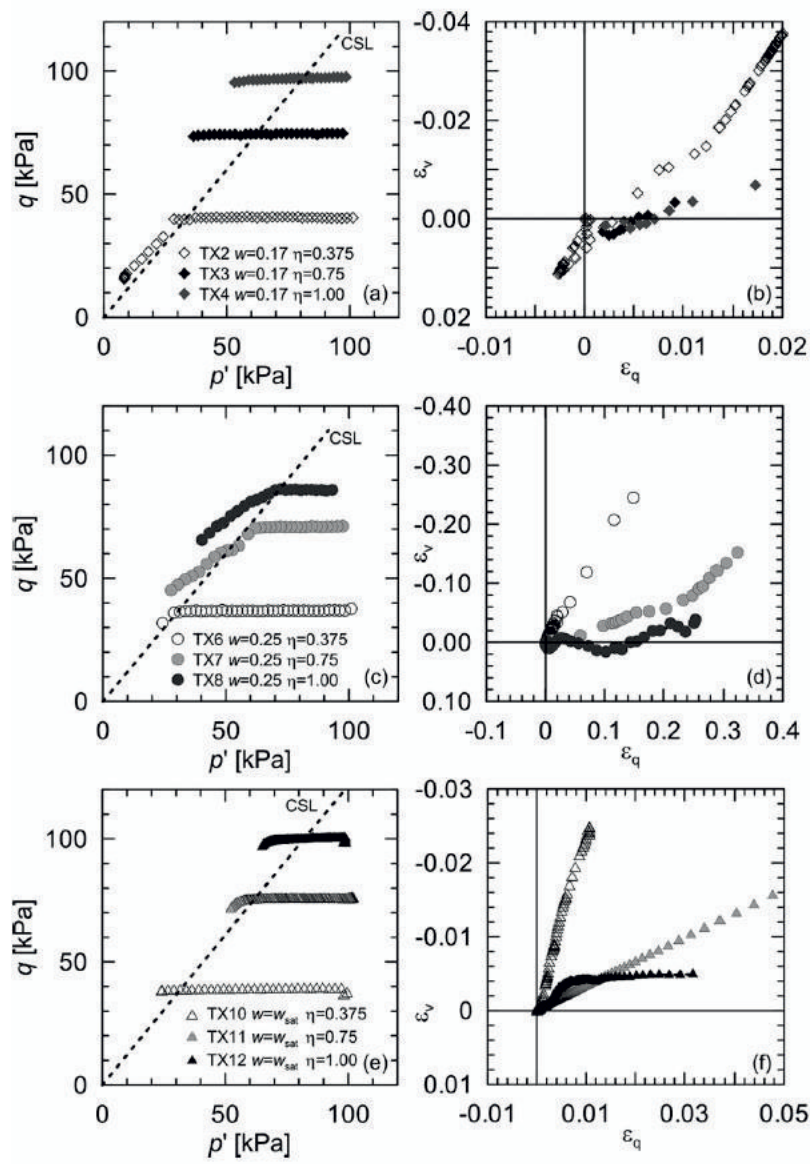

Figure 6. Constant axial load (CAL) phase: (a) $p^{\prime}-q$ plane $w=$ 0.17 ; (b) $\varepsilon_{\mathrm{q}}-\varepsilon_{\mathrm{v}}$ plane $\mathrm{w}=0.17$; (c) $p^{\prime}-q$ plane $\mathrm{w}=0.25$; (d) $\varepsilon_{\mathrm{q}}-\varepsilon_{\mathrm{v}}$ plane $\mathrm{W}=0.25$; (e) $p^{\prime}-q$ plane $w=w_{\text {sat }}$; (f) $\varepsilon_{\mathrm{q}}-\varepsilon_{\mathrm{v}}$ plane $w=w_{\text {sat }}$ (after [7]).
The framework is used to examine the influences of the stress state, void ratio, and degree of saturation on the stability behaviour of granular soils in slopes subject to saturation. The point representative of instability in the slopes under different water content and stress ratio at consolidation fits the trend of increasing $\eta_{\mathrm{IL}}$ with decreasing $e_{\mathrm{csl}}-e_{\mathrm{IL}}$ well. The bonding induced by partial saturation and different void ratios at the end of the consolidation phase explains the higher instability ratio exhibited by the samples with $\eta=0$ at decreasing water content (more details in [8]).

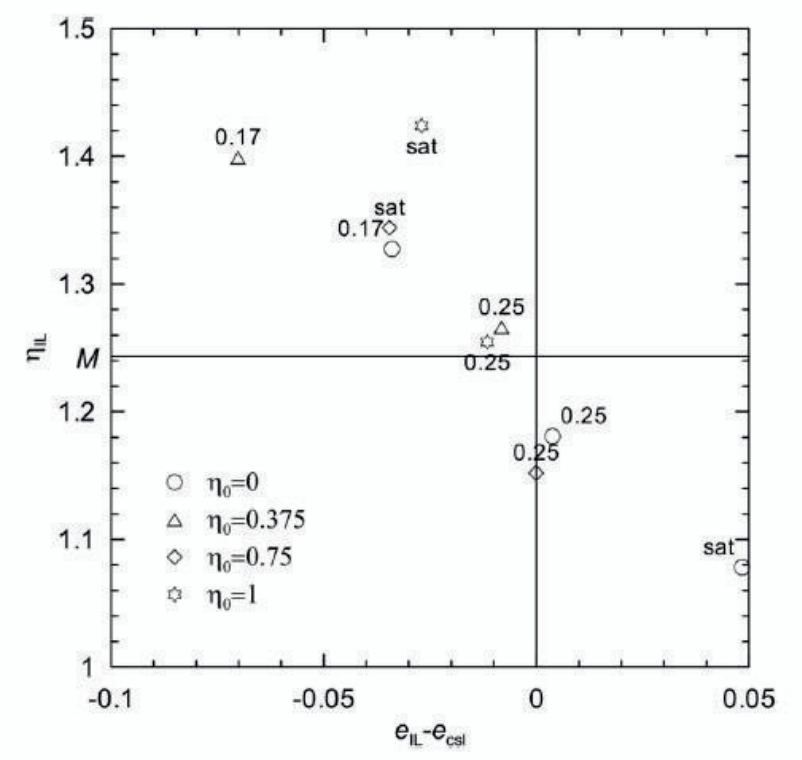

Figure 7. Potential instability line _ IL as a function of the distance $e_{\mathrm{IL}}-e_{\mathrm{cs}}$ : from unsaturated to saturated condition (after [7])

\subsection{Shear tests}

Direct shear tests have been performed on statically compacted specimens of Ruedlingen silty sand with a void ratio $e=0.90$ and three different gravimetric water contents of $w=0.15$, 0.20 and 0.25 . The experimental results and the Mohr-Coulomb envelope using the Bishop effective stress and the water retention curve (equation 1) are reported in Figure 8. The friction angle $\varphi^{\prime}=31^{\circ}$ is obtained from:

$$
\tau=\left(\sigma_{n}-u_{a}\right) \tan \varphi^{\prime}+S_{r}\left(u_{a}-u_{w}\right) \tan \varphi^{\prime}
$$




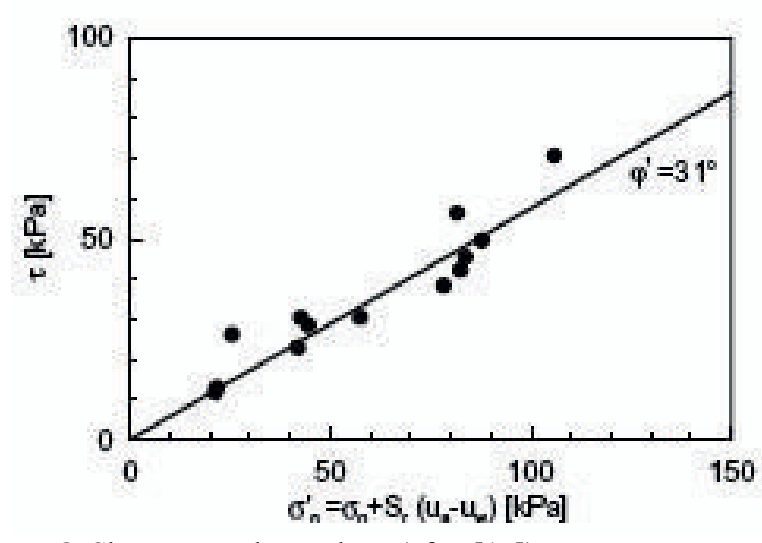

Figure 8. Shear strength envelope (after [15])

\subsubsection{Limit Equilibrium Analyses}

Based on the experimental results, a simplified slope stability analysis is carried out with shear strength parameters determined under unsaturated conditions for homogeneous ground. Extending the approach developed by [2] to a laterally limited slide, the factor of safety FoS becomes:

$F o S=\frac{\frac{c^{*}}{\cos ^{2} \alpha}\left(1+2 K \frac{z}{d \cdot \cos (\alpha)}\right)+\gamma z \tan \varphi^{\prime}\left(1+K \frac{z}{d \cdot \cos ^{3}(\alpha)}\right)}{\gamma z \tan \alpha}$

where $c^{*}=S_{\mathrm{r}} \quad\left(u_{\mathrm{a}}-u_{\mathrm{w}}\right) \quad \tan \varphi^{\prime}, \quad \alpha$ is the inclination of the slope, $\mathrm{z}$ the depth of the sliding surface, $\mathrm{d}$ the width of the slope, $K$ the earth pressure coefficient. The groundwater table is assumed to lie below the sliding surface and the shear resistance can be fully mobilised to depth $\mathrm{z}$ along the lateral sides, according to equation 2 .

In the following parametric evaluation of equation 2, a slope inclination of $\alpha=38^{\circ}$, $\gamma=\gamma_{\mathrm{s}} \cdot(1+w) /(1+e) \quad \gamma_{\mathrm{s}}=25.8 \mathrm{kN} / \mathrm{m}^{3}$, a width of $d=8 \mathrm{~m}$, a void ratio $e=0.9$ and an earth pressure coefficient of $K=1-\sin \left(\varphi^{\prime}\right) \quad\left(\varphi^{\prime}=31^{\circ}\right)$ were chosen as representative values for the field conditions.

The depth, for which the factor of safety (FoS) reaches unity, is plotted in Figure 9 versus the saturation degree. All points to the left of the curves represent stress states where the shear stress exceeds the shear resistance. Shallow slides are stable (to the right of the curve) due to the apparent cohesion provided by suction and degree of saturation, as represented by $c^{*}$, whereas very deep slides are unlikely to happen due to the friction mobilised on the base and side planes of the failure mechanism. The difference between drying and wetting conditions originate from different degrees of saturation and unit weight at the same values of suction.

When plotting the critical depth $\mathrm{z}(\mathrm{FoS}=1)$ versus the suction (Figure 10), the difference between the drying and the wetting branch of the WRC becomes less evident. During a rainfall event, the soil is saturated gradually. When a suction $\mathrm{s}=2.9 \mathrm{kPa}$ and $\mathrm{S}_{\mathrm{r}}=0.54$ are exceeded, a sliding surface is formed at a depth of about $1.12 \mathrm{~m}$.

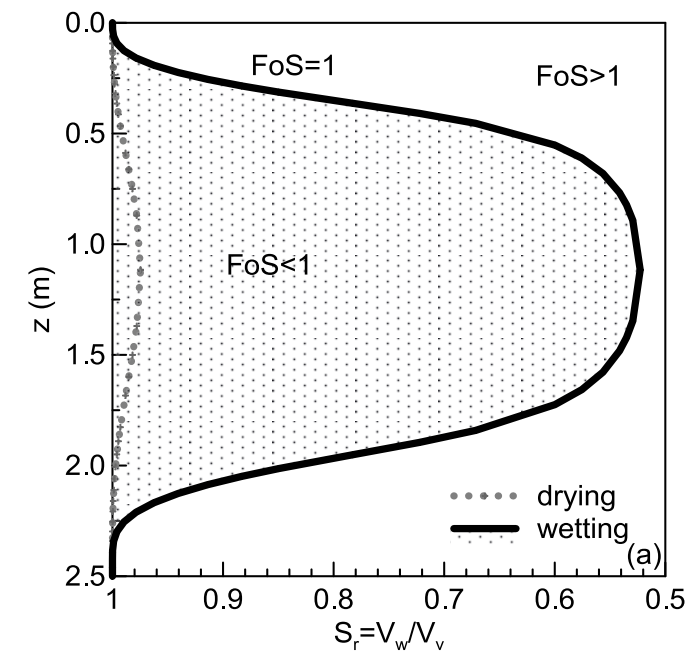

Figure 9 Depth $\mathrm{z}$ for $\mathrm{FoS}=1$ from Equation (2) as a function of saturation degree for conditions at cluster 3 (slope inclination $\alpha=38^{\circ}$, width $\mathrm{d}=8 \mathrm{~m}$, void ratio $\mathrm{e}=0.9$, earth pressure coefficient $K=1-\sin \varphi^{\prime}, \varphi^{\prime}=31^{\circ}$ ) (after [15]).

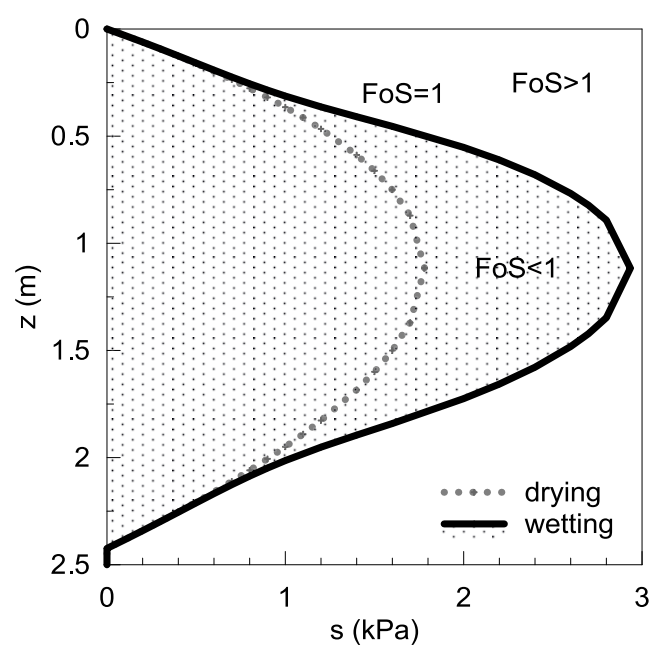

Figure 10 Depth $\mathrm{z}$ for $\mathrm{FoS}=1$ as a function of suction (after [15]) 


\subsubsection{Comparison with in situ behaviour}

The evolution of Volumetric Water Content (VWC) during the failure experiment is reported in Figure 11a at different depths in cluster 3 (see Figure 1). The evolution of pore water pressure recorded by piezometers $\mathrm{P} 4$ and P5, which were located inside the eventual failure zone, are also reported in Figure $11 \mathrm{~b}$. The TDR installed at a depth of $1.2 \mathrm{~m}$, which was the nearest instrument to the eventual slip surface, measured a decrease in water content about 1 hour before the failure (see [1,21]).

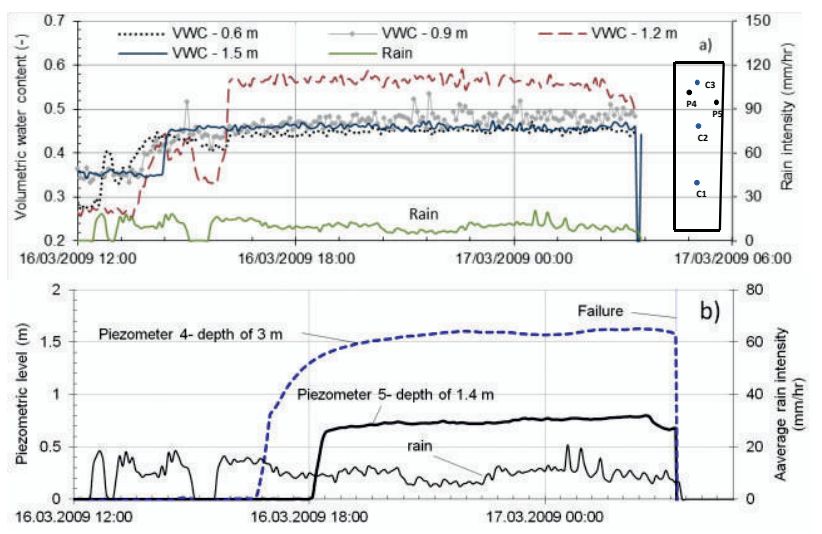

Figure 11 Time evolution during the landslide triggering experiment: a) volumetric water content in cluster $3-\mathrm{C} 3$; b) piezometric level at P4 and P5 (after [1])

The piezometers $\mathrm{P} 4$ and $\mathrm{P} 5$, which were located inside the eventual failure zone, also showed a decrease in the piezometric level (Figure 11b). Piezometer P4 is installed at a depth of $3 \mathrm{~m}$ from the slope surface and reacted faster to the start of rainfall and attained a higher value than P5. This response can be explained by the fact that this piezometer was installed in a higher location where more intense rainfall had been provided to the slope.

The observed decreases in the piezometric levels was more pronounced in P5 (approximately $0.12 \mathrm{~m}$ ), which was nearer to the failure surface. The decrease time corresponds well to the time when the VWC at $1.2 \mathrm{~m}$ also slightly decreased (about 1 hour before the landslide) [1].

These observed decreases in the VWC and piezometric level at the failure surface, before the landslide was triggered, can be attributed to the dilation of the soil at the failure surface, as observed also along the CADCAF stress path in triaxial cell (Figure 6).

The depth of failure and the pore water pressure acting on the slope are fairly well predicted by the limit equilibrium analyses, which account for an apparent cohesion dependent upon suction and saturation degree and have been extended to a lateral limited slide.

\section{Conclusion}

A field experiment has been performed on a steep forested slope with the aim to study the triggering mechanisms of landslides induced by rainfall.

The hydro-mechanical behaviour of the silty sand has been characterised in the laboratory and in situ through a wide range of tests conducted under saturated and unsaturated conditions. Since the average slope of the field exceeds the critical state internal friction angle, suctions developing through partial saturation play a fundamental role in stabilising the slope.

Partial agreement was observed comparing the in-situ values with a laboratory-derived WRC. Discrepancies could be attributed either to sampling effects or to drainage paths of different degrees of freedom: primarily one dimensional flow in small specimens in the laboratory, while three-dimensional flow will dominate under insitu conditions.

The soil exhibits dilatant behaviour along CADCAF stress paths, simulating the decreases of mean effective stress at constant axial force. This dilatant behaviour has been also confirmed from the in situ monitoring of volumetric water content and pore water pressure in the hour preceding the landslide.

The depth of the failure has been predicted with a simple Limit Equilibrium Analyse that accounts for a box-shaped failure mechanism and additional shear strength due to suction. The prediction agrees fairly well with the depth of failure observed in situ. 


\section{References}

1. Askarinejad, A., Casini, F., Bischof, P., Beck, A., Springman, S.M., Italian Geotechnical Journal, 3, 12 (2012)

2. Springman, S.M., Jommi, C., Teysseire P., Géotechnique 53, 1 (2003)

3. Lateltin O., Haemmig Ch., Raetzo H., Bonnard C., Journal of the International Consortium on Landslides, 2, 4 (2005)

4. Springman, S.M., Kienzler, P., Casini, F., Askarinejad, A. In Hamza M., Shaien, M., ElMossallamy Y. (eds): Proc. 17th International Conference on Soil Mechanics and Geotechnical Engineering, Egypt, 5-9 Oct.. IOS Press. (2009)

5. Brand, E.W., Premchitt, J., Phillipson, H.B. , Relationship between rainfall and landslides in Hong Kong. Proc. 4th Int. Symp. on Landslides 1 (1984)

6. Fannin, R.J., Eliadorani, A., Wilkinson, J.M.T., Géotechnique 55, 6 (2005)

7. Casini F, Serri V, Springman S. Canadian Geotechnical Journal; 50, 1 (2013)

8. Askarinejad, A., Casini, F., Kienzler, P., Springman, S.M., In Unsaturated Soils - Proc. 5th International Conference on Unsaturated Soils, Barcelona, Spain. Vol. 1 (2011)
9. Fischer, C., López, J., Springman, S.M. Intern. Conf. on Land., Hong Kong:. (2003)

10. Casini, F., Jommi, C., Springman, S.M. Granular Matter 12, 3 (2010)

11. Askarinejad, A., Failure mechanisms in unsaturated silty sand slopes triggered by rainfall DSc thesis, ETH Zurich (2013)

12. Casini, F, Canadian Geotechnical Journal 49, 8 (2012)

13. Minder, P., Semester thesis, ETH, Zurich (2008)

14. Colombo L., Master Thesis, Politecnico di Milano (2009)

15. Casini, F., Minder, P., Springman, S.M., In: Unsaturated Soils - Proc. 5th International Conference on Unsaturated Soils, Barcelona, Spain. Vol. 1 (2011)

16. Askarinejad, A., Beck, A., Springman, S.M. Canadian Geotechnical Journal. 52, 6 (2015)

17. van Genuchten MTh. Soil Science Society of American Journal 44 (1980)

18. Mualem, Y., Water Resour.Res., 9 (1973)

19. Chu J, Leroueil S, Leong WK. Canadian Geotechnical Journal 40 (2003)

20. Been K, Jefferies MG. Géotechnique 35, 2 (1985)

21. Springman, S.M., Askarinejad, A., Casini, F., Friedel, S., Kienzler, P., Teysseire, P., Thielen, A. Acta Geotechnica Slovenica, 1 (2012). 